\title{
Lexis
}

Journal in English Lexicology

1 | 2008

Polysemy

\section{The Null Instantiation of Objects as a Polysemy- Trigger. A Study on the English verb See}

\section{Maria Ivana Lorenzetti}

\section{(2) OpenEdition}

Journals

Electronic version

URL: http://journals.openedition.org/lexis/769

DOI: 10.4000/lexis.769

ISSN: 1951-6215

\section{Publisher}

Université Jean Moulin - Lyon 3

\section{Electronic reference}

Maria Ivana Lorenzetti, « The Null Instantiation of Objects as a Polysemy-Trigger. A Study on the English verb See », Lexis [Online], 1 | 2008, Online since 04 July 2008, connection on 01 May 2019. URL : http://journals.openedition.org/lexis/769 ; DOI : 10.4000/lexis.769

\section{c) (i) $९$}

Lexis is licensed under a Creative Commons Attribution-NonCommercial-NoDerivatives 4.0 International License. 


\title{
The Null Instantiation of Objects as a Polysemy-Trigger. A Study on the English verb See
}

Maria Ivana Lorenzetti ${ }^{54}$

\begin{abstract}
This paper argues that the phenomenon of the null instantiation of objects, i.e. the property of some transitive verbs to omit their direct complements, can be viewed as a polysemy-trigger. Our study, adopting a lexical complexity perspective, suggests that in the majority of cases verbs retain traits of their prototypical meaning, which becomes the starting point for possible inferences, contributing to the overall interpretative process, and leading to the dynamic emergence of different semantic interpretations and nuances through complex mechanisms of figure and ground.

Corpus-data on the verb see support the main typologies of null objects outlined, as well as the main factors attested to play a role in licensing null objects. Moreover, the deprofiling of the object in the case of a nuclear verb like see triggers the emergence of new pragmatic meanings, which cannot be derived from the lexical meanings of the various elements in a proposition taken in isolation, but which are interactionally-driven and surface in unpredictable ways, determining a progressive shift towards the cognitive dimension of the verb.
\end{abstract}

\footnotetext{
${ }^{54}$ University of Verona, Department of English Studies, University of Verona, Lungadige di Porta Vittoria 41, 37129 Verona (VR), Italy : mariaivana.lorenzetti@univr.it
} 


\section{Introduction}

Part of the interpretation of verb meaning crucially hinges on argument structure. Delineating the possible syntactic expressions of the arguments of a verb and accounting for why they are syntactically realised as they are across languages is a core issue at the syntaxsemantics interface.

A major challenge to theories of argument realization [Pinker 1989, Levin and Rapoport 1988; Levin 1993; Jackendoff 1990, Rappaport Hovav and Levin 1998] is represented by implicit direct objects, namely the instantiation of a referent without the overt expression of it.

The present contribution is aimed to explore the interaction between the argument structure of verbs and their meaning, in an attempt to shed some light on the changes occurring in the mapping process between conceptual and semantic structure, when a core element in the syntactic frame of the verb is missing. Our analysis suggests that argument omission can function as a polysemy-triggering device, leading to shifts in the meaning of prototypically transitive verbs.

Even though we argue that positing different lexical entries in the case of null-object verbs is often counterintuitive and inappropriate, we suggest that, even in cases of omitted arguments, verbs retain traits of their prototypical meaning. The latter becomes the starting point for possible inferences, contributing to the overall interpretative process, and leading to the dynamic emergence of different semantic interpretations and nuances through complex mechanisms of figure and ground ${ }^{55}$ [Talmy 2000].

The phenomenon is here applied to a corpus-based study of the English verb see, whose status as a nuclear verb in conjunction with its frequency of occurrence are regarded as two major driving forces for the rising of new constructions associated to meanings which progressively distance from basic perceptual see, and whose diverging trajectories cannot always be easily reconciled with the basic perceptual sense of the verb in a straightforward way. The semantic flexibility of see can be well captured by the notion of polysemy, whereby different senses can be activated, as a result of the dynamical interaction of the semantic components of perception, cognition and affect [Miller and Johnson-Laird 1976, Bertuccelli Papi 2003].

Our study of the implicit-object construction applied to the verb see shows that, while the verb displays the two main typologies of null objects outlined, in this case the licensing of null objects goes a step further. The conceptual-semantic structure of the verb and the syntactic construction dynamically interact, triggering the emergence of new pragmatic meanings, which cannot be derived from the lexical meanings of the various elements taken in isolation, or viewed as nuances permitted by the verb frame, but which are interactionallydriven and surface in unpredictable ways, determining a progressive shift towards the cognitive dimension of the verb.

\footnotetext{
${ }^{55}$ The first conceptualization of Figure and Ground is due to Gestalt Psychology, where it refers to a cognitive ability to separate elements based upon contrast, such as dark and light, black and white etc. This definition, however, is frequently expanded from simple perception based on contrast to include abstract (i.e. non-visual) concepts such as melody/harmony, subject/background and positive/negative space. The general conceptualization of figure and ground in language was proposed by Langacker [1987] and Talmy [2000]. For Langacker, figure designates the foregrounded entity in the trajector / landmark profile of a grammatical relation, while in Talmy's account of complex sentences, the figure is seen as a moving or conceptually movable entity, whose path or orientation is conceived as a variable, the particular value of which is the relevant one. The ground, on the other hand, is a reference entity which has a stationary setting relative to a reference frame, with respect to which the figure's path, site or orientation can be characterised.
} 
The phenomenon of the null instantiation of objects [Fillmore 1986] is here investigated against the framework of lexical complexity as introduced by Bertuccelli Papi [2003] and further developed by Bertuccelli Papi and Lenci [2007], in which words are viewed as "cues of mental representation, triggers of ad hoc conceptual constructions, and anchors which hinder meanings from verging on the border of chaos" [Bertuccelli Papi and Lenci 2007: 15].

In section 2 the theory of lexical complexity is presented, while section 3 introduces the phenomenon of the null instantiation of objects, providing a survey of the major typologies of null objects outlined in the literature. A classification of factors which contribute to licensing null objects is also proposed. The role of transitivity is examined in section 4 , while section 5 presents the results of a case study on the verb see. Empirical data for analysis have been taken from the British National Corpus (BNC) through the Sketch Engine Corpus Query System. Our conclusions are outlined in 6.

\section{The Theory of Lexical Complexity}

We owe to natural and social science a first conceptualization of complexity and the elaboration of theories on complex systems [Weaver 1948; Kauffman 1995; Strogatz 1994]. Cells, organisms, companies, supply networks, markets, societies, and hardware systems, despite their obvious differences are all examples of complex systems. Complex systems are systems in process that constantly evolve and unfold over time and are characterized as highly structured and displaying multiple interactions between many different components. Two major properties characterize a system, namely the level of the system complexity and the extent of its organization. According to Collier and Hooker [1999], complexity refers to "the number of independent pieces of information needed to specify a system", while "organization characterizes the extent of the interrelations among the components of the system in terms of their number, scope and dynamics".

That the lexicon of a language can itself be characterised as a complex system has been proved by a variety of studies [MacWhinney 2002; Elman 1995], all of which testify to the web of intertwined dimensions which need to be considered, when trying to explain how meaning is dynamically generated and understood in actual communication. Meanings differ for the type and number of their constitutive dimensions, as well as for their degree of interrelatedness. Moreover, features defining a concept can come from very different domains - e.g. perception, motion, functionality, social reality - and can vary in their degree of salience. For instance, in a framework such as the Generative Lexicon [Pustejovsky 1995, 2001], lexical entries are highly structured entities made up of multiple layers of information, each pointing at different conceptual dimensions of meaning.

Complexity at the lexical level can be evaluated on the basis of the types and quantity of information necessary to describe the meaning of a lexical item and the organizational properties of such information.

In this view, polysemy and context-sensitiveness are taken to be inherent properties of lexemes [Croft and Cruse 2004] and the disambiguation of senses or meaning construals is viewed as the result of the stable balance of the system at a given time. Lexical items, within this research framework, are characterised as complex dynamic microsystems [Bertuccelli and Lenci 2007], with a multilayered structure [Elman 2004], and can be conceived as "pointers to conceptual structure, out of which meanings are dynamically construed in context-sensitive modalities, following a non-linear process, but emerging in recurrent 
configurations with some degree of statistically relevant stability" [Bertuccelli Papi and Lenci 2007:21].

The lexical complexity approach, therefore, brings together both the claims of cognitive semantics that meaning is grounded in conceptual material [Croft and Cruse 2004], and the claim that meaning is to a certain extent compositional. Compositionality is dynamically viewed and does not refer to the analytical combination of necessary and sufficient semantic features, but to the synthesis of "portions" of conceptual information. Words act as pointers towards these "portions" of conceptual spaces in different contexts of usage, and the linguistic and extralinguistic context act as constraints that dynamically select the "portions" to be included in the construal of a certain "contextualized meaning" [Croft and Cruse 2004].

\section{The Null Instantiation of Objects}

In English, but also in other languages, a wide range of verbs appears to possess the property of omitting some of their arguments. A case in point is represented by the verb eat, which can occur either as a transitive verb, or in the traditional intransitive construction, as in and.

(1) Lucy ate an ice cream.

(2) James was eating.

(3) Mark does not want any pizza. He said he has already eaten.

Positing two different verbs eat - one transitive and the other intransitive - seems to be inappropriate and counterintuitive. Rather, we can assume that in the object has been left implicit, suggesting an activity reading, since as part of our knowledge of the world, we know that eating necessarily involves eating something, while in (3) a default inference favours the interpretation of eating as "having a meal".

Not all instances of object omissibility fall within the same category, however, since the phenomenon is typical of a wide range of verbs and verb classes.

Early accounts of the phenomenon proposed the elimination of the object from the syntax via "object deletion transformation" [Katz and Postal 1964, Browne 1971, Allerton 1975], while later works introduced the view that implicit object constructions have aspectual constraints [Mittwoch 1982] and that omitted objects are frequently typical, inferable or partially specified by the semantics of the verb [Lehrer 1970, Rice 1988].

Recent studies on the subject have been frequently biased towards particular research perspectives, leading to analyses in purely syntactic or semantic terms, while attempts to establish generalisations related to particular verbs or classes of verbs ultimately proved inadequate [Rappaport Hovav and Levin 1998], since many cases of null objects are highly context-dependent.

\subsection{Typologies of Null Objects}

While the phenomenon is highly composite in nature and defies a unique characterisation, it is possible to establish some generalisations regarding the typologies of null objects identified in the literature. Null objects are a rather heterogeneous set, and may be 
characterised by a variety of different factors, such as the verb class and the type of discourse constraints on their usage. For the sake of brevity, in the present contribution, we shall focus only on two of them, which appear as particularly significant, namely 'indefinite null objects' and 'definite null objects'. For a more detailed survey of null object typologies, see Lorenzetti [2006].

\subsubsection{Indefinite Null Objects}

This category, also known as Indefinite Null Complements (henceforth INCs) [Fillmore 1986] or Unspecified Object Alternation [Browne 1971], is typical of a variety of activity verbs of the eat type, such as drink, sing, bake, cook and paint among the others, which have a pronounced manner component in their meaning and fairly circumscribed selectional restrictions. Hence, the content of the null object is more or less predictable: it will correspond to the literal rather than to the metaphorical meaning of the verb, and is sometimes argued to be restricted in usage, i.e. an expression such as I'm cleaning Is most likely to refer to the interior of a house, rather than to one's teeth.

(4) I am reading. $\rightarrow$ a book/newspaper/printed or written material $/ *$ coffee grounds.

However, postulating a reading of these verbs in terms of stereotypic entities associated to them does not always seem appropriate, since while in example (3) the phantom object is a meal, i.e. the apparently stereotypic entity associated to the verb eat, in an example like the most likely context would not lead to the interpretation that the person is accustomed to having a meal or as many meals as she can during the whole day.

(5) I started working out, but I would eat all day after that.

On the contrary, the most typical interpretation in this case is likely to be achieved through the underspecified word "food", a representative of the entire class of edible things. However, the fact that the object is unexpressed in this case suggests that what the person eats is irrelevant for the current purpose of the interaction.

We can suppose, in this respect, that a better explanation of the restrictions on these null objects is that they have to be consistent with the underlying context, the intentional structure of discourse and the shared relevance [Sperber and Wilson 1986] at the time of utterance.

\subsubsection{Definite Null Objects}

Definite null complements, or DNCs in Fillmore [1986], are clearly contextual and are influenced by discourse factors, such as recoverability. It should be noted, however, that contextual factors are not the only relevant ones, since this alternation tends to be related to particular sets of verbs, i.e. speech act /cognition verbs (insist, object, observe, understand, think), perceptual and aspectual verbs (continue, stop), which select non-first order entities ${ }^{56}$

\footnotetext{
${ }^{56}$ According to the semantic classification of nouns proposed by Lyons [1977: 462-467], in an attempt to refine the traditional distinction between concrete and abstract nouns, first-order entities are physical objects, i.e. persons, animals and things and are classified in terms of their existence (ex. woman, dog, hand, car). Secondorder entities, on the other hand, are "events, processes, states-of affairs, which are located in time and which, in
} 
[Lyons 1977] as their objects, as in .

(6) He was walking quickly, but suddenly he stopped. $\rightarrow$ walking

Definite null object verbs constrain the null object to refer to a highly salient entity. For instance in the conversation in (7), the unexpressed object of call must be 'the person called' referred to by speaker $A$.

$$
\text { A - Ring, damn you. }
$$

B- I can't believe he didn't call.

A- Maybe he'll call, I don't know.

A.-When I talked to him, he seemed funny. Like, "I'll call you later, babe".

B. - He'll call.

A. - Do you think so?

(from the Script of the Movie Flashdance)

\subsubsection{Related Constructions and Phenomena}

Phenomena within the purview of the implicit object construction are highly complex and can be situated at the interface between syntax, semantics and pragmatics, and it is only through the interaction of knowledge from these three different domains with the relevant contextual information, that incomplete sentences can be properly interpreted.

In the light of the different research paradigms which tackled the problem of understood argument and of the previously outlined typologies of null objects, it appears that some generalisations can be made, as to the factors which are attested to play a prominent role in licensing null objects.

Several parameters seem to play a role in argument omission which can be roughly subdivided into two broad categories, namely lexical factors and discourse factors.

A relevant factor in determining whether a verb allows its object to be omitted appears to be the nature of the object itself in a broad sense. The presence or absence of an object may affect the type of state of affairs denoted by the predication [Vendler 1967], determining a shift from an activity to an accomplishment reading, as in (8) and (9).

(8) John is eating. (activity)

(9) John is eating an apple. (accomplishment)

Another relevant parameter pertains to the specificity of the omitted object, namely the capacity of a verb to take just one or a very limited range of objects. In this respect, as shown by Rice [1988], it appears that the more predictable a participant is, the more likely it is to be

English, are said to occur or take place, rather than to exist" [Lyons 1977:443] (ex. arrival, error, journey, contest). They are evaluated in terms of their reality. By third-order entities, we identify abstract entities, such as propositions, which are outside space and time and are evaluated in terms of their truth (ex. belief, idea, fact, hope). A further subclass in this classification is proposed by Hengeveld [1992], who introduces the category of fourth-order entities to identify speech-acts, which are evaluated in terms of their felicity conditions (ex. statement, question, order). 
deleted. Moreover, there seems to be a close relation between object omission and the semantic role of the omitted objects, as documented by Fillmore [1986].

Object omission has been frequently related to verb classes and to their semantic structure [Levin1993; Rappaport Hovav and Levin 1998]. Fellbaum and Kegl [1989], who put forward an analysis of understood objects on the basis of taxonomies, suggested that the semantic variability of a verb like eat, which allows both a transitive and an intransitive construction, is semantically motivated and can be explained by looking at the position of the verb in a taxonomic hierarchy. By taking a look at the verb troponyms ${ }^{57}$, they noticed that verbs such as nibble and dine are differently related to eat, in that the former represents a manner of eating, while the latter does not strictly refer to a manner, but rather to eating a substantial quantity of food at a certain time of the day.

This led them to posit two different semantic entries for eat, where eat $t_{1}$ is equivalent in meaning to eating a meal and behaves as if it had incorporated its cognate object; whereas eat $t_{2}$ is equivalent to ingest food in some manner. English possesses a number of verbs to indicate different kinds of meals, where the hyponym meal has been conflated with the verb, thus yielding to breakfast, to dine, to picnic etc. All of these verbs are intransitive, because they are specific lexicalisations of eat ${ }_{1}$. Other intransitive troponyms of the verb are mush, nosh and graze. They are not conflations of eat $t_{1}$ and the noun meal, but they are related to the verb, in that they refer to informal ways of eating a meal. By contrast, transitive eat $_{2}$ has the sense of ingest food in some manner, and all its troponyms refer to a specific manner of eating, e.g. gobble, gulp, devour. Syntactically, they argue, the manner expression is a prepositional phrase adjunct, which always requires the presence of a direct object at the level of the surface structure, which is why these verbs necessarily require direct objects.

The same situation is alleged to occur with drink, wash, draw and other related verbs. A corollary to this hypothesis is that omitted objects tend to belong to semantically neutral verbs as opposed to those which include a manner component.

Not only does semantic neutrality seem to play a role in object omission, but frequency of occurrence is also important, as suggested by Goldberg [2005]. Some verbs like smoke, drink, sing and write appear without an object even in situations which are not within the purview of the de-profiled object construction (i.e. when the action is particularly emphasised), since they occur in generic contexts and with an habitual interpretation (Pat smokes; Chris sings; John drinks). Goldberg argues that the frequent appearance of some verbs in those contexts apparently led to the grammaticalization of a lexical option, whereby they can appear intransitively in less constrained contexts, which amounts to saying that the frequent omission of an argument in a given context, which allows or favours the omission may lead to the creation of a new convention through a process of reanalysis. ${ }^{58}$

Moreover, supporting the idea that the high frequency ${ }^{59}$ of these verbs is responsible for

\footnotetext{
${ }^{57}$ Troponymy (from the Greek tropos, manner or fashion) defines a manner relation among verbs. Fellbaum and Miller, outlining the semantic network of English verbs called Wordnet, recognised that the identification of verb hyponyms is different from that of nouns, as exemplified by the fact that the "kind of" relation is not easily importable to the domain of verbs (cfr. A horse is a kind of animal is felicitous, but Mumbling is a kind of talking is not always so). Troponymy is a particular kind of entailment and can be expressed by the formula to V1 is to V2 in some particular manner.

${ }^{58}$ This line of thought is consistent with the claim [Bybee 1998; Hopper 1987] that 'meanings' are to be considered as generalisations from many repetitions of hearing predicates used in association with certain types of human events or situations over the course of a person's lifetime. Our brain is masterfully adapt at categorising and sorting new data and what can initially appear as an extension, loses this status after several hearings, thus showing how the dividing line between stored argument structures and extension is constantly changing.

${ }^{59}$ This is in accordance with the claim that the more frequent a predicate is, the less likely is it to have a fixed structure. The most frequent verbs in English, get, say, know, go, know, think, see, come, want, mean (Biber et al. 1999) are in fact reported not to have a fixed argument structure, but some are found in lexicalised expressions
} 
their reanalysis is the fact that verbs considered synonyms, but less frequent, do not allow object omission:

(10) a. Tom read / *perused last night

b. Tom wrote/*drafted last night.

Rice [1988] contends that the manner component adds a certain degree of specificity, which makes the verb lose its basic status. The impossibility of omission may be then considered to be related to specific semantic components shared by verbal sets, which might foster or forbid omission. In addition to the manner component, a feature like completion can also make a verb incompatible with object omission. By contrast, the duration component is frequently associated to object omission.

As to the factors more directly connected to the domain of discourse, it is worth mentioning the topic/focus distinction. The omitted arguments in (11) and the following are all highly predictable, and therefore they are not good candidate for focal status, since "the focus is that portion of a proposition which cannot be taken for granted at the time of speech, the unpredictable and pragmatically non-recoverable element in an utterance" [Lambrecht 1994: 207].

A sentence topic, by contrast, is usually defined as "a matter of already established current interest which a statement is about and with respect to which a given proposition is to be interpreted as relevant" [Lambrecht 1994: 119].

\footnotetext{
(11) a. I thought you said your dog doesn't bite!

b. Religion integrates and unifies.
}

Every sentence requires at least one focus, namely an assertion containing new information (Chafe 1994). It would be tempting to claim that when objects are omitted, the focus is on the activity itself.

Moreover, structural omission, i.e. determined by some linguistic constructions, which more readily favour object omission, deserves special mention. Among the most frequently cited constructions in the literature are contrastive focus (Pussycats eat, but tigers devour), fixed phrases (hit or miss), linking or sequential (You wash, I'll dry), iterated actions (The chef fried and baked all afternoon) and instructional imperatives (Take three eggs. Break into a bowl).

Finally, object omission is also enhanced by the extra linguistic context, which frequently provides clues as to the identification of the missing information. Frames in this respect prove to be of fundamental importance (Restaurant Script: the client entered, he ordered, he ate, he paid, he left).

and discourse markers and serve as a basis for innovation and variation (Croft 2000). 


\section{Transitivity}

The phenomenon of the null instantiation of objects is also crucially related to the problem of transitivity. Increasing interest in the idiosyncratic properties of particular sentence patterns in the last few decades emphasised the inadequacy of a rigid dichotomy between transitive and intransitive verbs, prompting scholars to revise the concept in favour of an 'emergentist' scalar approach.

The latter was proposed by Hopper and Thompson [1980], who, bearing on cross-linguistic evidence, argued in favour of a prototype approach to transitivity, viewed as emerging from the interaction of a cluster of properties concerned with the effectiveness with which an action takes place.

Each parameter (Table 1), focusing on a particular perspective, suggests a scale according to which clauses can be ranked, and taken together, they allow clauses to be classified as more or less transitive.

\begin{tabular}{|l|c|c|}
\hline \multicolumn{1}{|c|}{ PARAMETERS } & High & Low \\
\hline A. Participants & 2 & 1 \\
\hline B. Kinesis & action & non-action \\
\hline C. Aspect & telic & atelic \\
\hline D. Punctuality & punctual & non-punctual \\
\hline E. Volitionality & volitional & non-volitional \\
\hline F. Affirmation & affirmative & negative \\
\hline G. Mode & realis & irrealis \\
\hline H. Agency & A high in potency & A low in potency \\
\hline I. Affectedness of O & O highly affected & O not affected \\
\hline J. Individuation of O & O highly individuated & O not individuated \\
\hline
\end{tabular}

Table 1. The parameters of Scalar Transitivity [Hopper and Thompson 1980] ${ }^{60}$

On the basis of these parameters, Hopper and Thompson [1980] formulate the Transitivity Hypothesis:

If two clauses (a) and (b) in a language differ, in that (a) is higher in transitivity according to any of the features A-J, then, if a concomitant grammatical or semantic difference appears elsewhere in the clauses, that difference will also show (a) to be higher in transitivity. [Hopper and Thompson 1980: 255]

Two parameters are especially relevant for the purpose of this contribution, namely 'affectedness' and 'individuation of the object'. The former concerns the extent to which an action is more effectively transferred to a patient, while the latter has to do with "the distinctness of the patient from the agent as well as from its own background" [Hopper and Thompson 1980: 253]. Particularly, an object can be said to be highly individuated, if it possesses the following properties:

\footnotetext{
${ }^{60}$ The following abbreviations are employed: $A$, as in 'A high in potency' stands for AGENT, while $O$, as in 'Affectedness of O' refers to the OBJECT.
} 
- $\quad$ proper vs. common

- human/animate vs. inanimate

- concrete vs. abstract

- singular vs. plural

- count vs. mass

- referential, definite vs. non-referential

Considering two examples, such as and from the perspective of scalar transitivity, we can thus establish that clause is globally higher, on the basis of the properties of 'telicity', 'kinesis', 'total affectedness' and 'individuation' of the object.

(12) Jerry likes beer.

(13) Jerry hit Sam.

\section{The Intrinsic Polysemy of the Verb See}

See is generally regarded as basic among the verbs of vision and is correspondingly frequent in speech and writing. According to cognitively-oriented studies on their semantic content (Miller \& Johnson-Laird 1976, Bertuccelli Papi 2003), verbs of vision have been proved to be shaped around three basic conceptual components, 'perception', 'cognition' and 'affect'. The dimension of 'affect', which is more prominent in a group of verbs (spy, ogle, goggle and leer among the others), refers to the positive or negative quality of the evoked emotion, its intensity and the presence of a motivation.

In the case of see, these conceptual components are responsible for the possible meaning nuances of the verb, but do not enjoy the same status, and 'perception' is assumed as the basic dimension, also contributing to shaping the semantic space covered by the other two dimensions, as well as their mutual relationship (Figure 1).

(14) He saw many armed soldiers marching in the street. (perception)

(15) She saw the difficulty of winning, but still insisted on bringing it to a vote. (cognition)

(16) He saw her hungry and cold in the street. (perception and cognition)

(17) He had a girl last year, but he's not seeing anyone now. (affect) 


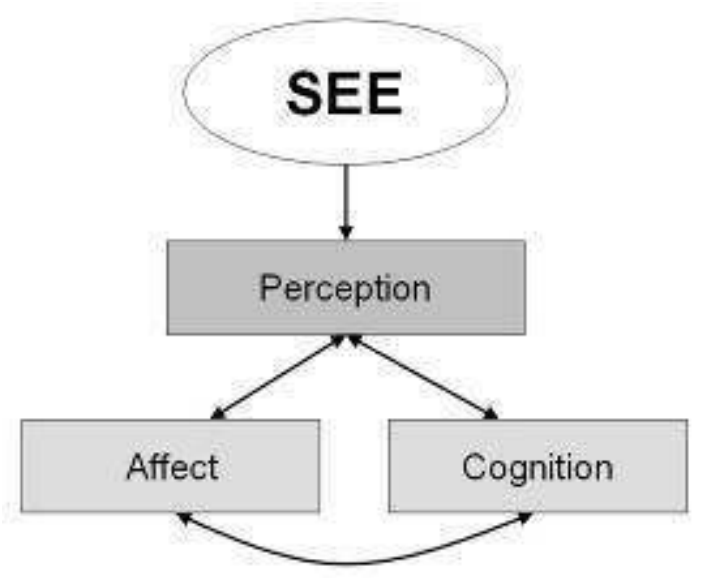

Figure 1. The Conceptual Dimensions of $S E E$

According to lexical acquisition studies [Bowerman 1976], see is acquired relatively early by children, and appears to be one of the basic communicative tools in early interactions between children and adults. This might lead to hypothesise that its syntax and semantics be very simple. If we examine a corpus of sentences containing the verb see and attempt to determine the senses from these data, we notice that in almost half of the instances, in which the verb is followed by complementation, its typical frame includes a noun phrase as subject, typically a human being, and a noun phrase in direct object position, typically referring to a physical object (18). By contrast, other elements such as manner of perception, location of the perceiver, direction and background against which perception is experienced are considered peripheral and consequently optional. This might be conceived as the indefeasible valency potential of the verb which, even out of any specific linguistic context, and in cases when some of the core arguments might be left unspecified, is felt to hint at a full propositional structure.

(18) Jane saw a car.

On closer inspection, however, we can also notice that the rest of the syntactic constructions in which the verb occurs is surprisingly varied. Human beings tend to recur in subject position, but the 'seer' can also be animals, or even inanimate objects, such as computers, or places etc. (The radar cannot see through the mountains, but it can see storms; House prices in London saw their lowest February rise in five years). The highest degree of variation is represented by verb complementation, since the 'seen' can also be represented by abstract entities, states, events of various types and propositions.

A list of the basic verb complements associated to the verb is represented in Table 2. This list of complements was derived from my observations of complementation patterns encountered in corpus occurrences, conjointly with valence patterns reported in the FrameNet database and in Wordsketch, in the Sketch Engine.

As it is apparent from the list outlined, there is consistent variation as to the complementation patterns occurring with see, and more patterns can be generally associated to more than one sense of the verb.

In an attempt to establish some preliminary distinctions, we can say that constructions 1-28 are mainly concerned with the visual sense of the verb, whereas constructions 29-37 can be said to be primarily focused on non-visual senses. 


\begin{tabular}{|c|c|}
\hline $\begin{array}{l}\text { Complementation } \\
\text { Pattern }\end{array}$ & Examples \\
\hline 1. none & She could barely see. \\
\hline 2. NP & $\begin{array}{l}\text { a. Jane saw the cat. } \\
\text { b. 'I see your problem", said Georgiades, after a moment's reflection. }\end{array}$ \\
\hline 3. NP AP & I had never seen him so angry. \\
\hline 4. NP V-ing & She saw him running to the stairs. \\
\hline 5. NP VP & I saw her take it. \\
\hline 6. (That) clause & Alice saw (that) the keys were missing. \\
\hline 7. if-whether clause & They wanted to see if it had stopped snowing. \\
\hline 8. WH-indirect question & $\begin{array}{l}\text { a. The children wanted to see what their parents were eating. } \\
\text { b. I don't see why I should stick around and be made to pay too. }\end{array}$ \\
\hline 9. NP PP [above] & Over his shoulder, I could see the air above the lift doors flick on n.4. \\
\hline 10. NP PP [across] & She could see fly across his face. \\
\hline 11. NP PP [along] & I can see both ways along the bridge. \\
\hline 12. NP PP [behind] & Ace could see movements behind the windows of the shuttle. \\
\hline 13. NP PP [beneath] & They were beginning to see the truth beneath the facade of propaganda. \\
\hline 14. NP PP [beyond] & $\begin{array}{l}\text { For this reason we can see a little way beyond the horizon even on the } \\
\text { Earth. }\end{array}$ \\
\hline 15.NP PP [from] & "Can you see the blackboard from the back of the room?" \\
\hline 16. NP PP [inside] & The door was ajar and Patrick could see movement inside the room. \\
\hline 17. NP PP [on] & "I know I'd love to see my name on the cover of a magazine." \\
\hline 18. NP PP [outside] & He was too deeply into the part to see anything outside the stage. \\
\hline 19. NP PP [through] & He couldn't see the road through the rain. \\
\hline 20. NP PP [under] & Someone will see the light under the door. \\
\hline 21. PP [behind] & $\begin{array}{l}\text { From that position he had a panoramic view over a large part of the } \\
\text { course and he could see behind as well as forward. }\end{array}$ \\
\hline 22. PP [inside] & No one had ever been there, no one had ever seen inside. \\
\hline 23. PP [over] & He cannot see over tall buildings. \\
\hline 24. PP [beyond] & $\begin{array}{l}\text { The adventurers must head for it, even though they can't be sure that } \\
\text { the haze and mist they see beyond the archway offers any real hope of } \\
\text { release. }\end{array}$ \\
\hline 25. PP [from] & We couldn't see much from the window. \\
\hline 26. PP [in] & $\begin{array}{l}\text { They may be able to see in the dark, sense compass direction, and } \\
\text { recognise danger. }\end{array}$ \\
\hline 27. PP [into] & Through this hole, I could see into the room next to the hut. \\
\hline 28. PP [through] & What Cardiff saw through those windows brought him to a halt. \\
\hline 29. PP [off] & $\begin{array}{l}\text { In the end the NL did become demonstrably pro-Conservative and saw } \\
\text { off the IML challenge. }\end{array}$ \\
\hline 30. PP [to] & Sarah will see to the dogs, while we are away. \\
\hline 31. PP [about] & It's getting late - I'd better see about lunch. \\
\hline $\begin{array}{l}\text { 32. that-clause/to it that- } \\
\text { clause }\end{array}$ & $\begin{array}{l}\text { I'll see that the pavement gets cleaned. } \\
\text { I'll see to it that the dinner is ready by } 8 \text {. }\end{array}$ \\
\hline
\end{tabular}




\begin{tabular}{|l|l|} 
33. NP PP (To) & He'll see you to the door. \\
\hline 34. passive V-to & They have been seen to disregard the rules. \\
\hline 35. NP PP (as) & This is a factor which many will see as a major advantage. \\
\hline $\begin{array}{l}\text { 36. PP (in) NP or NP PP } \\
\text { (in) }\end{array}$ & Those gestures can be seen in some Persian miniatures. \\
\hline 37. BE seeing NP & Are you seeing someone lately? \\
\hline
\end{tabular}

Table 2. Complementation syntactic patterns of see

While the first pattern displays an intransitive construction in which the faculty-reading of the verb is highlighted, the second one (2a.) referring to the perceptual sense of see represents the prototypical instance of the verb complementation. Pattern 3 goes a step further, in that it also focuses on some mental process of interpretation of a given situation. The fourth and fifth patterns focus respectively on the imperfective and perfective readings of the verb. Pattern 6 displays a factive reading [Kiparsky and Kiparsky 1971], where that could be substituted by the fact that. By contrast, in 7 the verb is followed by if, and suggests that the perceiver aims to verify some previous hypotheses, while in 8 he or she just wants to know the outcome of a certain situation.

Patterns 9 to 31 report usages of the verb when followed by prepositions. The latter might refer either to the position of the object or phenomenon viewed, or to that of the perceiver. On closer inspection, however, we observe the presence of some ambiguous cases, even within constructions more directly related to visual perception in a strict sense (pattern 13). In addition, it must be pointed out that many of the syntactic constructions outlined for visual perception can also be employed in cases of metaphorical readings ("He saw the truth inside his heart"; "They were very friendly, but I quickly saw through them") of the verb, or in cases when a more cognitively-oriented reading is in focus. This is the case of complementation patterns $2 \mathrm{~b}$. and $8 \mathrm{~b}$., where the direct object is not a concrete and referential noun phrase, but an abstract entity.

Many see occurrences in these patterns do not merely or even mainly deal with actual visual perception, which in some cases does not seem to be included at all.

More specifically, the senses of see seem to refer to the concept of polysemy, and as a consequence, it is not surprising that one sense of the verb can sometimes be felt to encompass meaning qualities that make it possible to associate it with more than one propositional use.

\subsection{Null Objects and See}

On the basis of the parameters of scalar transitivity outlined by Hopper and Thompson [1980], as well as those concerning agent and patient proto-roles [Dowty 1991], the verb in its perceptual sense can be ranked in middle position along a transitivity scale, since it displays the following properties:

- It presupposes two participants;

- Both $\mathrm{NP}_{1}$ and $\mathrm{NP}_{2}$ usually represent referential entities, and are designated by common or proper nouns;

- $\mathrm{NP}_{2}$ is highly individuated; 
- The verb admits both perfective and non-perfective readings;

- The action can be either punctual or non-punctual;

By contrast, the subject and the object of the verb do not conform to the characteristics of proto-agent and proto-patient, the subject represents an experiencer-passive and the object can hardly be classified as highly affected.

While this might be conceived as the indefeasible valency potential of the verb, and its primary meaning, the range of syntactic constructions in which see can occur is consistently varied.

Corpus analysis and evidence from spoken language downgrade claims regarding the position of see as a mid-transitive verb, since it behaves as a 'low-content verb' [Chafe 1994], and occurs as the head of a wide variety of fixed phrases, and dispersed predicates, in which the object is either non-referential or omitted.

This datum, however, does not represent a contradiction, since as repeatedly reported in a wide range of studies [Biber et al. 1999 among the others], highly frequent verbs tend to be employed as the basis for new constructions, and are difficult to be assigned argument structure unequivocally.

Three kinds of usages can be outlined in the case of the verb, in conjunction with null objects, namely one related to the faculty of vision in a generic sense, elliptical usages and a cluster of collocational phrases and idiomatic usages typical of conversational style.

\subsubsection{The Faculty Reading}

The first type of usage is typically related to the faculty meaning of the verb, which denotes ability to perceive by a given modality, rather than focusing on the perception of something in particular, and can be included in INCs. This usage might be reasonably considered as a primary sense, but is in fact treated only as a secondary instance of see, probably on the ground that visual perception in considered as a prerequisite condition.

(19) I cannot really see without my glasses on.

(20) Sometimes at night, the fog is so thick, that you can hardly see from one end of the bridge to the other.

Objectless instances of see in the faculty sense tend to occur in conjunction with modals can and could, as in (19) and (20), focusing on ability, and especially when the predication is negated, since this sense of the verb is usually invoked to suggest some sort of difficulty or limitation of vision.

\subsubsection{Elliptical Usages}

Another usage of the verb in conjunction with null objects, and whose implicit content can be easily recovered from the context of utterance, is more directly associated to DNCs (see 2.1.2.). 
(21) "What the hell are you doing up so early?" he demanded." "It's not early." "It damn well is!" He extended his wrist. "See? Half-five."

(22) The sand started to rise up like a cloud of dust. "What is it? “, Blake started to ask, and then he saw. From around the throne, something was unravelling its body. It was hundreds of feet long, initially resembling a huge snake uncoiling itself.

Usages like those reported in and can be regarded as elliptical, even though the exact wording of the understood object constituents cannot be unequivocally determined for all of them. Although it seems relevant to notice that certain constructions occurring in this sense appear to be more oriented towards a cognitive reading, as in , the majority of elliptical usages outlined represent instances of the perceptual sense of the verb.

(23) I had to do something that time, don't you see? I couldn't just leave it.

\subsubsection{Collocational Phrases}

The verb also tends to occur in a variety of expressions, which in the linguistic literature have been variously labelled as 'pragmatic markers', 'discourse markers', or 'prefab chunks' [Jucker and Smith 1998], whose literal meaning is assumed to influence their discourse use and functions. While some of them could be included in DNCs, and be classified as elliptical instances of the verb, they are designed to embody specific communicative functions in language. Therefore, in our view, they are better captured as a separate instantiation of object omission.

\subsubsection{You See}

This pragmatic marker is by far the most frequent form in which the verb see is encountered in the corpus, 11655 hits on a total of 185151 of see occurrences. But it can also be found in the slightly different, but nonetheless related forms y'see, see?, and you see?, as in , and.

(24) [...] but then again right, y' know, I can understand some o' the words which she says to me y' know -- I even speak it back to her, $\mathbf{y}^{\prime}$ see.

(25) Madame Gautier looked up and caught Ellie's eye just for a moment, and the glance seemed to say, See? See what the world can hold? And then Madame Gautier picked up her Waterford glass and took a sip of her wine.

(26) Doyle looked at Tug almost sadly and spoke not to him, but over his head, to the Woman.' You see? Make a pattern and people step into it. As long as the pattern lasts. Don't you remember interrupting like that to stop your parents quarrelling?"

It is typical of spoken discourse, especially of the informal type, while it is less frequently employed in written language, unless when the writer aims at involving the reader, in imitation of the typical characteristics of verbal exchanges. 
Far from being merely a parenthetic vocative to address the hearer and ensure that he or she is paying attention to what is being said, the functions performed by you see are strongly related to issues such as common ground [Clark 1996], face [Goffman 1967] and directivity [Searle 1976]. It can be employed to direct the addressee towards a certain interpretation, or to introduce one's point of view, as a turn-taking device.

(27) You see, there are no more hysterical discussions. Now, after three changes of government, people are calmly discussing the future.

(28) Rab didn't know what to say. "You see, people just didn't trust me." Rab still didn't know what to say. "My eyes." Doctor said. "I see," Rab said. "But I don't think you understand."

A peculiar characteristic of you see is that of being employed whenever a potentially tricky or controversial issue is being introduced, as in, where the speaker attempts to mitigate a facethreatening act, by softening his utterance.

(29) He gathered his robe up around his knees and smiled at her. "Now I must leave you," he said gently. "My people, you see, are awaiting me."

In addition, the marker can be used to clarify one's position, justify one's behaviour, or to assure the hearer of something .

(30) I think it's, I think it's err, I'm just getting old. See, I'm used to doing everything myself. Mhm. I've always had to do everything.

(31) Think how terrible it is to be blind! But how lucky you've got a free place at Redmond College! I can't give you any money, you see. All our money's gone, and I can't work now.

(32) Then she stared, amazed, at the fragile rosebud lying across his palm. "See, I won't harm you", he said, smiling down at her bemused face.

In final position, the primary use of you see is that of ensuring the hearer's comprehension, but it also serves to issue some comments on topics at stake in the interaction. In this case, we could argue, you see functions at the metalinguistic level, and the speaker expresses his attitude towards the content of the proposition or towards the addressee, by typically showing one's disagreement in the form of a comment, or of an emphatic request of understanding .

(33) Yanto brought the machine to a screeching halt outside the Salvation Inn. "See, I told you," grunted Billy, pointing at the pub's unlit portals, "they're closed."

(34) "I 'm OK." “And what about school today?" "I told ya. I don't have to go. It's a holiday, see, it's a holiday! I told yaw!" His voice had become high, almost hysterical.

The functions performed by this marker, which also vary depending on its position in the utterance, are thus centred on the role of the speaker, and seem to range from mere phatic appeal, to questions ensuring the hearer's understanding of the signal, and further of the 
illocutionary force of the utterance, with the perlocutionary intent of exerting pressure and control over the hearer.

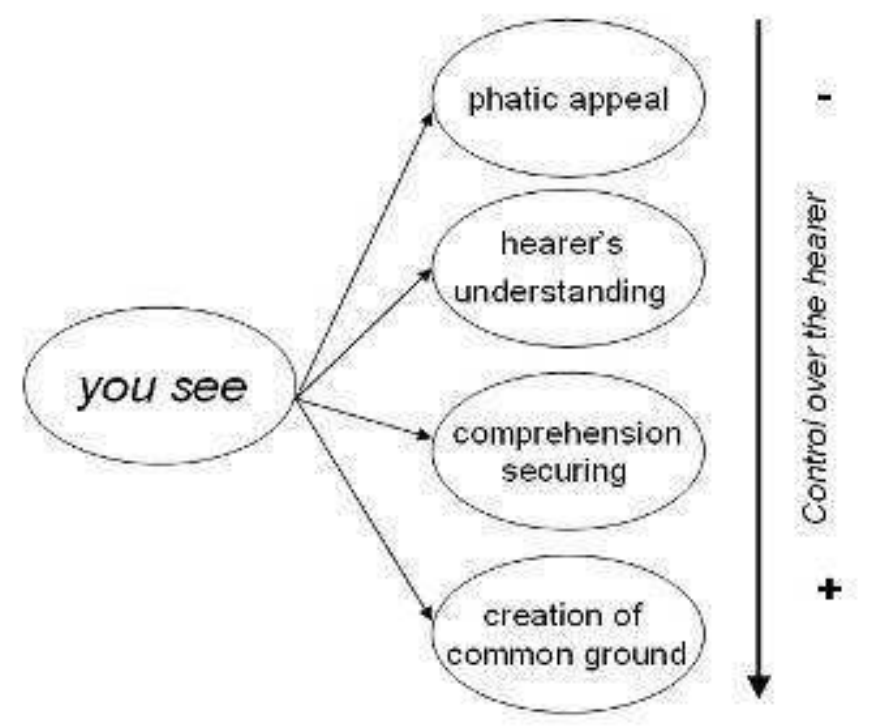

Figure 2. Range of Pragmatic Functions of You See

\subsubsection{I see}

I see is also widely spread in the conversational domain, where it serves a variety of different pragmatic functions. As for the speaker-related functions, we can affirm that you see and you know can be located in a comparable pragmatic space, on account of their sharing a variety of functions [Schiffrin 1987, Jucker and Smith 1998]. By contrast, regarding the hearer-related functions, there seems to be only partial overlapping between the pragmatic import of I see and the most widely used reception marker Yeah.

Some scholars, who conceive you see as a watered-down parenthetical, (most notably AlmArvius 1993) bearing only a slight connection with perceptual see, argue that I see has richer descriptive meaning and appears as "less adulterated", probably suggesting that its connection with the primary sense of the verb is stronger and more apparent in this expression. As a consequence, it is felt to be more acceptable as a self-sufficient contribution to a conversation, while the former, it is claimed, can hardly constitute a separate turn in itself.

Its pragmatic functions range from mere back-channel cue, to the signalling of uptake .

(35) "It's a, come in here. I'll show you. When you're do it dry. You noisy little bugger! Then put the top on." "Oh! Alright." "Put your filter like that. You put your bag on that." "Oh! I see. Yeah." "See what I mean?" "Yeah."

(36) "Don't you get any sick payment or" "Well, I've just come up and the accident, so I 'm only entitled to money for the first four days." "I see. And when are you likely to be earning again?"

However, I see can also be used as a sympathy marker, or to issue ironic or disapproving comments . 
(37) "But why move into a dump like that?" I tried to explain, and she was more understanding than I had expected. “Oh, I see! You felt you weren’t good enough to be anywhere nice!"

(38) Ellen replied in a slightly peevish tone. "Miletti's death was nothing to do with you, surely?" "That remains to be proved." "Oh, I see. It's the old story. You're guilty until proven innocent."

Regarding the functional import of I see, we can observe that its pragmatic scope ranges from mere phatic marker, to feedback marker, confirming one's understanding, which can also take place all of a sudden, and can be related to specific information, or to general interactional units. In addition, it can also be employed as a turn-keeping device, or an utterance incompletor, enabling the current speaker to retain the turn.

On a cognitive-expressive plan, it can function as a comprehension confirming device, or as an expressive device marking support or surprise, as an emphatic comment. But it can be applied to signal one's disagreement, through the exploitation of ironic discourse as well (Figure 3).

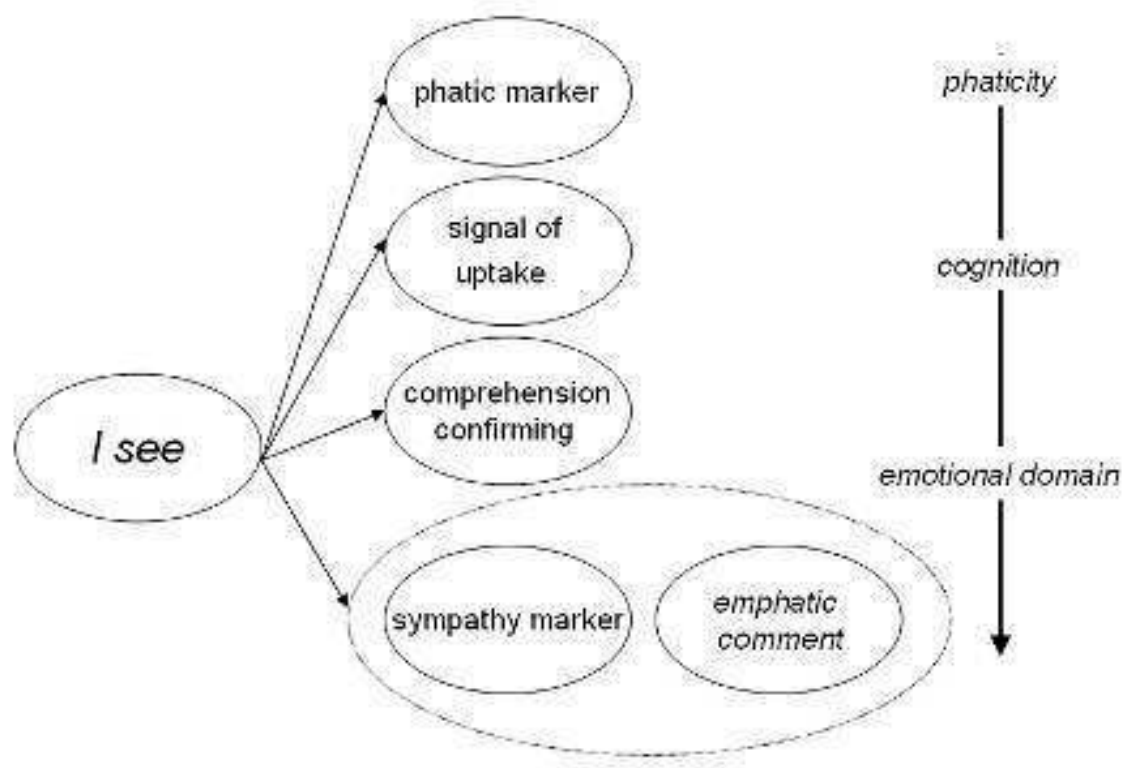

Figure 3. Basic Functions of I see

\subsubsection{I'll see, We'll see and You'll See}

These expressions refer to future acts, and are differently shaped, depending on the interaction of the verb, with the future auxiliary will and the various pronominal subjects. I'll see focuses on the role of the speaker as an agent, and might refer to an act of selfdeliberation, whereby the latter indicates that he shall consider and adequately assess a situation at stake. The pronoun $I$ in this case has a role of exclusivity and the implicit meaning typically attached to such an expression is "I'll decide what to do, but the final decision is entirely up to me". 
(39) Kelly cursed her job, thinking how nice it would be to have someone she trusted holding her. "Leave early." "I'll see," she said. But she'd already made up her mind.

In addition, the marker may communicate the speaker's unwillingness to comply with a request by another interlocutor .

(40) The Professor combed his beard thoughtfully. "I will see what can be done," he said. "I can promise nothing; but I'll see."

Agentivity, directivity and intentionality are crucial notions in this respect, and part of the pragmatic meaning of the expression, profiling a situation in which the speaker has a certain social authority over the addressee, is conveyed by the use of the future tense.

We'll see focuses on the role of the speaker as well, and is frequently employed in situations in which the hearer is in a subordinate position of some sort, typically in parent/child talk exchanges, when parents do not want to grant immediate permission to do something. In this case, the pronoun we is employed in a hearer-exclusive fashion, as part of a negative politeness strategy [Brown and Levinson 1987].

(41) “Can we go to Wagner's ice-cream parlour?" Anna asked. "We'll see. For now you must lie down on the bed and go to sleep."

As for the expression you'll see, it usually serves an inherently directive function. On the one hand, it can be employed to direct the addressee towards a certain interpretation, signalling the speaker's confidence that his claims regarding a certain matter will be proved right, while it can also be employed in commissive acts of various kinds, promises, assurances, or even threats.

(42) He began to move his hand towards his mask. "We're men from the Navy. You'll be all right now. I "m going to take my respirator off. You'll see." As his hand closed on the rubber border, the man appeared to steady, staring fixedly, as if fascinated by the spectacle.

\subsubsection{Let me see and Let us See}

In the case of these two markers, the overall pragmatic import emerges as the result of compositionality, and precisely from the relation of the imperative mood in conjunction with let and the two different pronouns.

The main function of let me see is that of a 'filler', or 'utterance-incompletor', in the socalled 'ratiocinative questions', whereby the speaker sets him/herself to organizing about a given situation.

(43) "I can understand that, Mrs Wilson. It has been a long time. When was it that you left for Naples?" "Naples let me see. It would have been 1935 or 1936."

Let us see, on the other hand, is more centred on an attention-directing function. This pragmatic meaning is conveyed by the use of $u s$ as an 'in-group marking' device [Brown and 
Levinson 1987], whereby the speaker creates common ground with the addressee, suggesting that the requested act serves to promote cooperation.

(44) "It will be a simple matter to reset it." With a deft motion of surprisingly nimble fingers, he shifted the misaligned parts back into their correct placing. "Now, let us see." Concentrating once again on the central mirror, he focused his will on the device itself, and its past.

The concept of discourse marker has been frequently invoked to explain the pragmatic import of the expressions examined in the previous sections, on the ground that they derive from original lexical meanings, are multifunctional at both the textual and interpersonal level, in discourse function are semantically bleached [Sweetser 1988], and form a separate tone unit. Establishing the meaning that the verb see acquires in these various contexts does not seem to be so straightforward. Likewise it is difficult to determine the extent to which the perceptual component of the verb can still be recovered as part of the pragmatic import of these constructions. One of the most debated issues regarding these phrases is the way in which they developed their functions, since their origin is that of semantically complete elements.

\section{Conclusions}

In this contribution, we have argued that the phenomenon of the null instantiation of objects is best characterised within a revised notion of transitivity to be conceived as a scalar property of utterances, and emerging from the interplay of a cluster of parameters [Hopper and Thompson 1980]. The latter, however, do not display the same degree of salience, and only some of them, such as agentivity, affectedness and individuation of the object are assumed to have a primary role in this respect.

Moreover, it has been hypothesised that it is only as a result of the weakening of strong constraints on transitivity, which occurs when parameters such as agentivity and affectedness of the object exhibit low values, that other competing parameters related to the context are brought into play.

These observations are borne out by our analysis of see in relation to the phenomenon. The verb, which is usually ranked in middle position along a scale of transitivity, since both its subject and its object lack the property of proto-agent and proto-patient, can be employed intransitively in various contexts.

See possesses a variety of semantic dimensions and, similarly to other verbs of vision, it displays the tendency to extend its meaning to the neighbouring field of cognition. Both its status as a nuclear verb and its consequent frequency of occurrence are generally viewed as two major driving forces for the rising of new constructions, associated to meanings which progressively distance from perceptual seeing, and whose diverging trajectories cannot always be easily reconciled with the basic sense in a straightforward way. While, we have hypothesised that the constitutive conceptual dimensions of the verb are never cancelled in its many senses, but only "perspectivized", new mechanisms are brought into play, when the verb occurs in the implicit object construction.

The phenomenon of null objects, which can be characterised as a "locus of emergence" of syntactic, semantic and pragmatic properties, introduces additional levels of complexification. 
See can occur in a variety of fixed phrases, or crystallised constructions, designed to embody specific communicative functions in the language, such as monitoring discourse or pursuing the smooth outcome of a conversation (Figure 4).

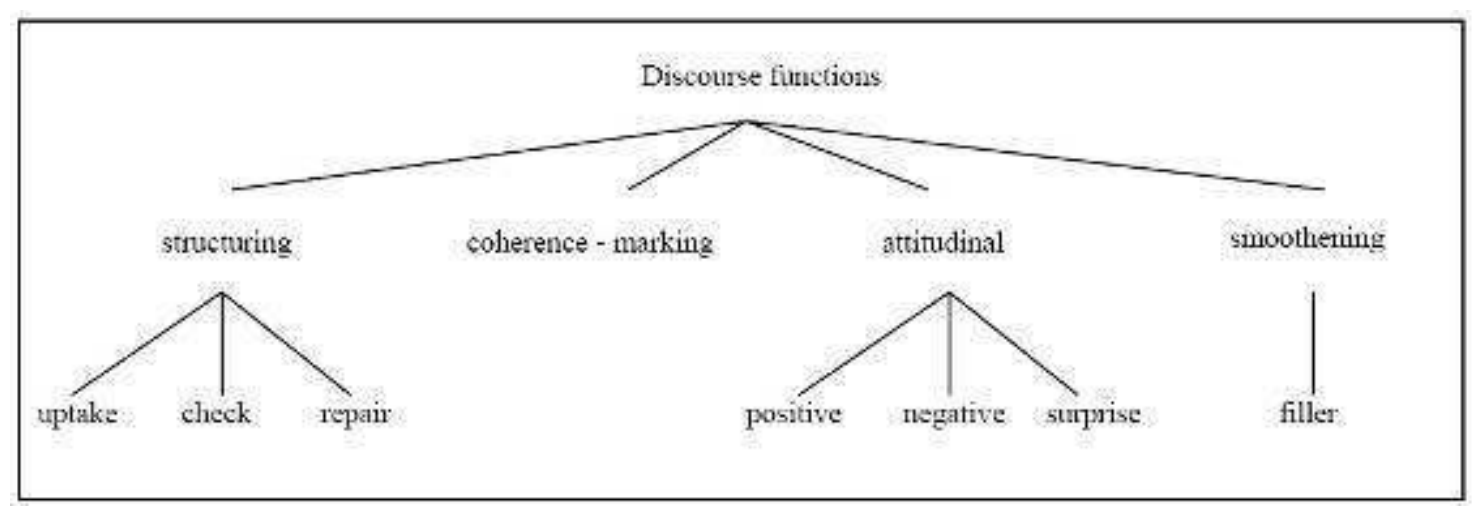

Figure 4. Typologies of Functions of Collocational Phrases with See

The communicative meaning of the verb in these syntactic constructions is functionallydriven and emerges as a result of compositionality and of implicatures related to issues of social deixis, through the interaction of pronouns such as you and $I$, and of different tenses, and it is not always easy to trace the inferential chains relating these pragmatic instances of see to its basic perceptual sense. On the contrary, the overall meanings of these expressions, which are interactionally-driven, surface in unpredictable ways and cannot be derived from the lexical meanings of the various elements taken in isolation.

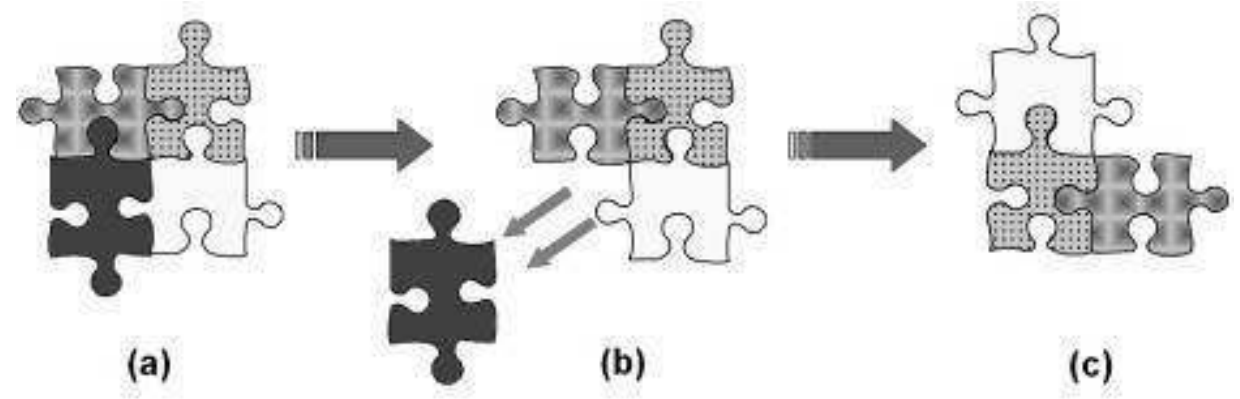

Figure 5. The Implicit Object Construction and Consequent Changes in the Structure of Lexical Items. ${ }^{61}$

Language radically underdetermines the rich interpretations regularly assigned to naturally occurring utterances. A consequence of this is the assumption that lexical entries, albeit crucial, act merely as prompts for meaning construction and that meaning construction is

\footnotetext{
${ }^{61}$ In Figure 5 we have attempted to present the different stages implied in the implicit object construction. By presupposing that meaning emerges in compositionality with the other elements in the syntactic frame, (a) represents the stage in which all the core syntactic elements of a verb are 'profiled' (Langacker 1987), while in (b) the demotion of a syntactic element is displayed, and finally (c) shows that the inner meaning constituents of the verb have undergone a process of reorganization, following object-omission. For practical purposes, so as to convey a clearer idea of the process hypothesised, a graphical visualization, showing meaning as tesseras of a puzzle has been adopted. This, however, is not meant to suggest any additional claim on the inner structure and organization of lexical items.
} 
largely a conceptual process, involving elaboration and integration of linguistic and nonlinguistic information in a highly creative way.

The deprofiling of a core syntactic element (Figure 5) of the verb in the case of see ultimately leads to the reorganization of the semantic topography of the verb, generating a complexification in the mechanisms of mapping from conceptual structure to lexical form and can thus be viewed as a polysemy-trigger, since the three semantic components responsible for shaping up meaning nuances of the verb are blended in unpredictable ways. The extent of such complexification needs not be the same for different sets of verbs and must be further explored.

\section{References}

Allerton David J., "Deletion and Pro-Form Reduction", Journal of Linguistics 11, 1975: 233 237.

Alm-Arvious Christina, The English Verb 'See'. A Study in Multiple Meaning, Göteborg, Sweden, Acta Universitatis Gothoburgensis, 1993.

Bertuccelli Papi Marcella, "Cognitive Complexity and the Lexicon", in Merlini Barbaresi Lavinia (Ed.), Complexity in Language and Text, Pisa, Edizioni Plus, 2003: 67-115.

Bertuccelli Papi Marcella and Alessandro Lenci, "Lexical Complexity and the Texture of Meaning", in Bertuccelli Papi Marcella, Cappelli Gloria and Masi Silvia (Eds.), Lexical Complexity: Theoretical Assessment and Translational Perspectives, Pisa, Edizioni Plus, 2007: 15-33.

Biber Douglas, Stig Johnasson, Geoffrey Leech, Susan Conrad and Edward Finegan, The Longman Grammar of Spoken and Written English, London, Longman, 1999.

Bowerman Melissa, "Semantic Factors in the Acquisition of Rules for Word Use and Sentence Construction", in Morehead Donald M. and Morehead Ann E. (Eds.), Normal and

Deficient Child Language, Baltimore, MD., University Park Press, 1976: 99-179.

Brown Penelope and Stephen Levinson, Politeness. Some Universals in Language Usage, Cambridge, Cambridge University Press, 1987.

BRowne Wayles, "Verbs and Unspecified NP Deletion", Linguistic Inquiry 2, 1971: 259-260.

BybeE Joan, "Mechanisms of Change in Grammaticization: The Role of Frequency", in Janda Richard and Josephs Brian (Eds.) The Handbook of Historical Linguistics, Oxford, Blackwell, 1998: 602-623.

ChнFе Wallace, Discourse, Consciousness, and Time: The Flow and Displacement of Conscious Experience in Speaking and Writing, Chicago, IL., The University of Chicago Press, 1994.

Clark Herbert H., Using Language, Cambridge, Cambridge University Press, 1996.

Collier John and C. A. Hooker, "Complexly Organized Dynamical Systems", Open Systems and Information Dynamics 6, 1999: 241-302.

CROFT William, Explaining Language Change: An Evolutionary Approach, Harlow, Essex, Longman, 2000.

Croft William and D. Alan Cruse, Cognitive Linguistics, Cambridge, Cambridge University Press, 2004. 
Dowty David, "Thematic Proto-Roles and Argument Selection", Language 67, 3, 1991: 547619.

Elman Jeffrey, "Language as a Dynamical System", in Port Robert F. and Van Gelder Timothy (Eds.) Mind as Motion: Explorations in the Dynamics of Cognition, Cambridge, MA., MIT Press, 1995:195-223.

---, “An Alternative View of the Mental Lexicon", Trends in Cognitive Science, 7, 2004: 301306.

Fellbaum Christiane and Judy Kegl, "Taxonomic Structures and Cross-category Linking in the Lexicon", ESCOL'89, 1989: 93-104.

Fillmore Charles J., "Pragmatically Controlled Zero Anaphora", Proceedings of the $12^{\text {th }}$ Annual Meeting of the Berkeley Linguistics Society, Berkeley, CA., BLS, 1986: 95-107.

Goffman Erving, Interaction Ritual: Essays on Face-to-Face Behavior, New Brunswick, NJ., Transaction Publishers, 1967.

Goldberg Adele, "Constructions, Lexical Semantics, and the Correspondence Principle: Accounting for Generalizations and Subregularities in the Realization of Arguments", in Erteschik-Shir Nomi and Rapoport Tova (Eds.) The Syntax of Aspect. Deriving Thematic and Aspectual Interpretation, Oxford, Oxford University Press, 2005: 215236.

Hengeveld Kees, Non-verbal Predication, Berlin, Mouton de Gruyter, 1992.

Hopper Paul J., "Emergent Grammar", Proceedings of the 13th Annual Meeting of the Berkeley Linguistics Society, Berkeley, CA., BLS, 1987: 139-157.

Hopper Paul J. and Sandra A. Thompson, "Transitivity in Grammar and Discourse", Language 56, 1980: 251-299.

JACKENDOFF Ray, Semantic Structures, Cambridge, MA., MIT Press, 1990.

Jucker Andreas H. and Sarah W. Sмiтh, "And people just you know like 'wow': Discourse Markers as Negotiating Strategies", in Jucker Andreas H. and Ziv Yael (Eds.), Discourse Markers. Descriptions and Theory, Amsterdam, John Benjamins, 1998: 171201.

Katz Jerrold and Paul Postal, An Integrated Theory of Linguistic Description, Cambridge, MA., MIT Press, 1964.

Kauffman Stuart A., At Home in the Universe: the Search for Laws of Self-Organization and Complexity, Oxford, Oxford University Press, 1995.

Kiparsky Paul and Kiparsky Carol, "Fact", in Steinberg Danny B. and Jacobovits Leon (Eds.), Semantics. An Interdisciplinary Reader in Philosophy, Linguistics and Psychology, Cambridge, Cambridge University Press, 1971: 345-369.

Lambrecht Knud, Information Structure and Sentence Form. Topic, Focus and the Mental Representations of Discourse Referents, Cambridge, Cambridge University Press, 1994.

Langacker Ronald W., Foundations of Cognitive Grammar, Vol.1, Stanford, CA., Stanford University Press, 1987.

LeHrer Adrienne, "Verbs and Deletable Objects", Lingua 25, 1970: 227-253.

Levin Beth, English Verb Classes and Alternations. A Preliminary Investigation, Chicago, IL., The University of Chicago Press, 1993.

Levin Beth and Tova Rapoport, "Lexical Subordination”, CLS 24, Part 1, 1988: 275-289. 
LoRenzetTi Maria Ivana, The Null Instantiation of Objects at the Syntax-SemanticsPragmatics Interface, Doctoral Dissertation, The University of Pisa, 2006.

Lyons John, Semantics, Cambridge, Cambridge University Press, 1977.

MAC Whinney Brian, "Language Emergence", in Burmeister Petra, Piske Thorsten and Rohde Andreas (Eds.), An Integrated View of Language Development - Papers in Honor of Henning Wode, Trier, Wissenshaftliche Verlag, 2002:17-42.

Miller George and Philip N. Johnson-Laird, Language and Perception, Cambridge, MA., Harvard University Press, 1976.

Miттwосн Anita, "On the Difference between Eating and Eating Something: Activities versus Accomplishments", Linguistic Inquiry 13, 1982: 113-122.

PINKER Steven, Learnability and Cognition: The Acquisition of Argument Structure, Cambridge, MA, MIT Press, 1989.

Pustejovsky James, The Generative Lexicon, Cambridge, MA., MIT Press, 1995.

---, "Type Construction and the logic of Concepts" in Bouillon Pierrette and BUSA' Federica (Eds.) The Syntax of Word Meaning, Cambridge, Cambridge University Press, 2001.

Rappaport Hovav Malka and Beth Levin, "Building Verb Meanings" in Butt Miriam and Geuder Wilhelm (Eds.) The Projection of Arguments. Lexical and Compositional Factors, Stanford, CA., CSLI Publications, 1998: 97-134.

Rice Sally, "Unlikely Lexical Entries", Proceedings of the $14^{\text {th }}$ Annual Meeting of the Berkeley Linguistics Society, Berkeley, CA, BLS, 1982: 202-212.

SCHIFFrin Deborah, "Information and Participation: y'know and I mean", in Discourse Markers, Cambridge, Cambridge University Press, 1997: 267-311.

Searle, John R., "A Classification of Illocutionary Acts”, Language in Society 5, 1975:1-23.

Sperber Dan and Deirdre Wilson, Relevance. Communication and Cognition, Oxford, Blackwell, 1986.

Strogatz Steven H., Nonlinear Dynamics and Chaos: with Application to Physics, Biology, Chemistry and Engineering, Reading, Perseus Books, 1994.

Sweetser Eve, "Grammaticalization and Semantic Bleaching", Proceedings of the 14th Annual Meeting of the Berkeley Linguistics Society, Berkeley, CA., BLS, 1988: 389405.

Talmy Leonard, Towards a Cognitive Semantics, Cambridge, MA, The MIT Press, 2000.

Vender Zeno, "Verbs and Times" in Linguistics and Philosophy, Ithaca, N.Y., Cornell University Press, 1967: 97-121

Weaver Warren, “Science as Complexity”, American Scientist 36, 1948: 536. 


\section{Sources of Examples}

\section{Corpora and Other Lexical Resources}

The British National Corpus, version 2 (BNC World) 2001, Distributed by Oxford University Computing Services on behalf of the BNC Consortium, URL:

(http://www.natcorp.ox.ac.uk/).

The FrameNet Database, The University of California, Berkeley, CA.

(http://framenet.icsi.berkeley.edu/index.php?option=com_frontpage\&Itemid=1)

SkE. The SKETCH Engine Copyright (C) 2006 Lexical Computing Ltd, Brighton (http://www.sketchengine.co.uk/)

\section{Scripts}

Flashdance Script (http://www.script-o-rama.com/movie scripts/f/flashdance-scripttranscript-jennifer-beals.html) 